\title{
Deficiency of natural anticoagulant proteins C, S, and antithrombin in portal vein thrombosis: a secondary phenomenon?
}

\author{
N C Fisher, J T Wilde, J Roper, E Elias
}

\begin{abstract}
Background-Hereditary deficiencies of natural anticoagulant proteins are implicated in the pathogenesis of portal vein thrombosis (PVT). Secondary deficiencies of these proteins have also been reported in PVT, making interpretation of concentrations difficult.

Aims-To characterise the coagulation profiles in adult patients with PVT and to investigate the possible mechanisms of natural anticoagulant protein deficiency.

Patients-Twenty nine adult patients with portal hypertension caused by PVT, and normal biochemical liver function tests. Methods-Routine coagulation profiles and concentrations of proteins $C, S$, and antithrombin were measured; where indicated, corresponding concentrations in parents were also measured. Synchronous peripheral and hepatic or splenic vein concentrations were compared in seven patients undergoing interventional procedures, as were peripheral concentrations before and after shunt surgery in three patients.
\end{abstract}

Results-Deficiencies of one or more of the natural anticoagulant proteins occurred in 18 patients $(62 \%)$, with six patients having combined deficiency of all three proteins. There were strong correlations between prothrombin and partial thromboplastin time ratios and concentrations of natural anticoagulant proteins. Family studies in nine cases of anticoagulant protein deficiency revealed possible hereditary deficiency in only three cases, and significantly lower concentrations of anticoagulant proteins in all PVT cases compared with parents. Levels of anticoagulant proteins tended to be lower in hepatic veins but higher in splenic veins compared with peripheral vein concentrations. Peripheral concentrations decreased after shunt surgery.

Conclusions-Deficiency of natural anticoagulant proteins is common in PVT and is probably a secondary phenomenon in most cases, occurring as part of a global disturbance of coagulation variables. The mechanism for this remains unclear but may result from a combination of reduced hepatic blood flow and portosystemic shunting itself. (Gut 2000;46:534-539)

Keywords: portal vein thrombosis; extrahepatic portal hypertension; natural anticoagulant protein; protein C; protein $S$; antithrombin
Portal hypertension owing to portal vein thrombosis (PVT) usually presents as unexpected variceal haemorrhage or splenomegaly with peripheral blood cytopenias. There may be a history of abdominal inflammatory disease with or without a prothrombotic condition such as pregnancy or oral contraceptive usage. Regardless of whether or not there is an associated precipitant, patients presenting with PVT should also be investigated for an underlying thrombophilic condition such as a myeloproliferative disorder or a hereditary thrombophilic state. Hereditary thrombophilias that are known to predispose to PVT include certain mutations of the prothrombin or factor $\mathrm{V}$ genes, or deficiency of one of the natural anticoagulant proteins $\mathrm{C}, \mathrm{S}$, or antithrombin..$^{1-5}$ However, diagnosis of hereditary natural anticoagulant protein deficiency is difficult if there is impaired liver function. Furthermore, reduction in circulating concentrations of natural anticoagulant proteins has been reported in patients with PVT, even in the presence of biochemically normal liver function and it has been suggested that in many patients these deficiencies may be acquired as a consequence of the PVT. ${ }^{6}$ Thus individuals with reduced concentrations of natural anticoagulant proteins in this setting cannot be assumed to have a hereditary deficiency state. The aims of this study were to characterise the coagulation profiles and concentrations of natural anticoagulant proteins in a cohort of adult patients with PVT; to determine whether deficiencies, if detected, are primary or secondary; and to elucidate the possible mechanism of acquired natural anticoagulant protein deficiencies.

\section{Patients and methods}

Case records of 42 adult patients with radiologically proved extrahepatic PVT or non-cirrhotic portal hypertension with intrahepatic portal sclerosis (NCPHT), a disease which probably has a similar pathogenesis to extrahepatic PVT, were analysed. ${ }^{8}{ }^{\text {The fol- }}$ lowing patients were excluded: eight patients with abnormal liver function as defined by persistently abnormal serum albumin or aspartate aminotransferase (AST) concentrations (normal ranges: at least $36 \mathrm{~g} / 1$, and $40 \mathrm{U} / 1$ or less, respectively); five patients who had undergone portosystemic shunts prior to investigation, as we later discovered that therapeutic portosys-

Abbreviations used in this paper: NCPHT, non-cirrhotic portal hypertension; PT, prothrombin time; PTT, partial thromboplastin time; PVT, portal vein thrombosis. 
temic shunting influences concentrations of coagulation proteins.

Twenty nine patients were therefore included in the study, of whom 26 had extrahepatic PVT and three had NCPHT. All patients had negative serological tests for viral or autoimmune hepatitis, genetic haemochromatosis, and Wilson's disease; alcoholic liver disease was excluded by careful history and liver histology. The patients were further categorised as follows: group 1-childhood presentation and/or history of umbilical vein sepsis $(\mathrm{n}=5)$; group 2-adult presentation without any history of abdominal surgery or inflammatory disease $(n=13$, including two patients with NCPHT); and group 3-adult presentation with known history of pancreatitis and/or upper abdominal surgery $(n=11$, including one patient with NCPHT). The median age at presentation in these groups was: group 1, 13 years (range 1-24); group 2, 35 years (range 17-56); group 3, 41 years (range 23-63).

Two patients in group 2 were using oral contraceptives and two patients in group 3 had known myelofibrosis prior to presentation. The modes of presentation were variceal haemorrhage $(n=21)$, splenomegaly and/or cytopenia $(n=5)$, ascites $(n=2)$, or transient jaundice owing to choledochal varices $(n=1)$. All patients were over 16 years of age at the time of this study; the median delay between first presentation and laboratory investigation was five years (range 0-26).

Contrast angiography was performed to confirm and document extent of portal vein thrombosis in most patients; in a minority of cases the diagnosis was made by non-invasive imaging with colour Doppler ultrasonography and/or magnetic resonance angiography. The extent of thrombosis of portal, mesenteric, and splenic veins was documented. Liver histology was obtained in 21 patients and was reported normal or near normal in all patients apart from three; in two of these there was fibrous expansion of portal tracts and in the third patient (who had jaundice owing to choledochal varices) there was histological evidence of cholestasis but no other abnormality. Patients were managed by variceal sclerotherapy or banding alone $(n=12)$, surgical splenorenal shunting $(n=3)$, splenorenal or portocaval shunting with splenectomy $(n=1$ each), splenectomy alone $(n=3)$, transjugular intrahepatic portosystemic shunt (TIPSS) insertion $(\mathrm{n}=2)$, and medical treatment alone or no intervention $(n=7)$.

\section{COAGULATION PROFILES}

The following coagulation variables were measured for this study (normal ranges given in parentheses where applicable): full blood count including platelet count $\left(150-400 \times 10^{9} /\right.$ 1), prothrombin (PT) ratio (1.2 or less), activated partial thromboplastin (APTT) ratio (0.8-1.2), protein $\mathrm{C}$ activity (660-1220 $\mathrm{U} / \mathrm{dl})$, free protein $\mathrm{S}$ antigen $(680-1460 \mathrm{U} / \mathrm{dl})$, antithrombin activity (750-1400 U/dl), activated protein $C$ (APC) resistance ratio (more than 2.6), and lupus anticoagulant screen using the dilute Russell's viper venom (DRVV) assay ratio (less than 1.1). Molecular analysis for the factor V Leiden mutation was performed in 26 patients, and for the prothrombin gene (G20210A) mutation in 10 patients (representing one, four, and five patients from groups 1 , 2 , and 3 respectively). Myeloproliferative disease was sought by bone marrow biopsy if suspected by peripheral blood count and blood film analysis. In nine patients with increased PT ratios, concentrations of factor VII (normal range 500-1500 U/dl), fibrinogen (1.5-4.0 $\mathrm{g} / \mathrm{l}$ ), and D-dimers (less than $250 \mathrm{ng} / \mathrm{ml}$ ) were measured, in order to determine whether this was owing to procoagulant protein deficiency or disseminated intravascular coagulation.

In the majority of cases two measurements of each variable were made at different timepoints, with a mean taken of the two values obtained. Protein C and antithrombin were measured by chromogenic assay (Immuno Ltd, Austria); protein $S$ was measured by enzyme linked immunosorbent assay (ELISA; Dako Ltd, UK). APC resistance was measured by the Coatest assay (first generation assay, Chromogenix $\mathrm{AB}$, Sweden). Factor $\mathrm{V}$ and prothrombin gene analyses were performed using in house polymerase chain reaction (PCR) techniques. Fibrinogen was measured by Clauss (Immuno Ltd), factor VII by a one stage clotting based technique, and D-dimers by a latexagglutination serial dilution assay (Accuclot, Sigma Ltd, UK).

FAMILY STUDIES

If a deficiency of any of the natural anticoagulant proteins C, S, or antithrombin was found, blood samples were obtained from both parents of the index cases where possible, to determine whether the deficiency was hereditary.

\section{COAGULATION PROFILES IN SELECTED VENOUS} BEDS

In selected patients who underwent transjugular liver biopsy $(n=3)$, TIPSS insertion $(n=1)$, or splenorenal shunts $(n=3)$, synchronous blood samples were taken from peripheral, hepatic, and splenic veins where possible for measurement of coagulation profiles in order to determine whether differences could be detected in different splanchnic venous beds in comparison with peripheral veins. For comparative purposes, synchronous peripheral and hepatic vein blood samples were also analysed from 15 patients with established parenchymal liver disease (mostly because of alcoholic cirrhosis) with portal hypertension undergoing transjugular liver biopsy or TIPSS insertion.

COAGULATION PROFILES BEFORE AND AFTER PORTOSYSTEMIC SHUNTING

Three patients underwent elective splenorenal shunt surgery (with preservation of the spleen) for definitive management of varices during the study period. In all cases, there was no active variceal haemorrhage at the time of surgery. In these patients coagulation profiles and natural anticoagulant protein concentrations were measured before and at least two months after 
Table 1 Spearman correlation coefficients ( $r$ values) for anticoagulant proteins, prothrombin time (PT) and acitivated partial thromboplastin time (APTT) ratios, and albumin in patients with portal vein thrombosis

\begin{tabular}{llllll}
\hline Protein S & $+0.47^{\star}$ & & & \\
Antithrombin & $+0.75^{\star \star \star}$ & $+0.60^{\star \star}$ & & \\
PT ratio & $-0.72^{\star \star \star}$ & -0.11 & $-0.46^{\star}$ & & \\
PTT ratio & $-0.65^{\star \star}$ & -0.21 & $-0.59^{\star \star}$ & $+0.76^{\star \star \star}$ & \\
Albumin & -0.04 & +0.17 & -0.17 & +0.01 & +0.11 \\
& Protein C & Protein S & Antithrombin & PT ratio & PTT ratio \\
\hline
\end{tabular}

${ }^{\star} \mathrm{p}<0.05,{ }^{\star \star} \mathrm{p}<0.01,{ }^{\star \star \star} \mathrm{p}<0.001$. Correlation coefficients where no $\mathrm{p}$ values are given were not statistically significant.

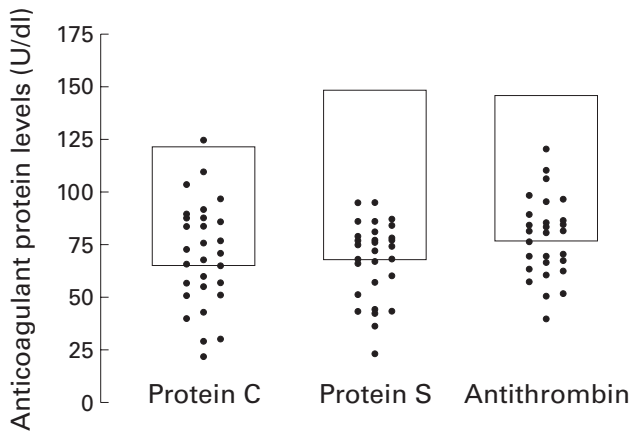

Figure 1 Scatterplot of protein $C$, $S$, and antithrombin concentrations in 29 patients with portal vein thrombosis. The box outlines indicate normal ranges (protein $C$ : 660-1220 U/dl; protein S: 680-1460 U/dl; and antithrombin: $750-1400 \mathrm{U} / \mathrm{dl}$ ).

surgery in order to determine whether portosytemic shunting influenced these values.

STATISTICAL ANALYSIS

Statistical analysis was done with SPSS statistical software, using the Mann-Whitney U test, Wilcoxon rank sum, Kruskal-Wallis, and Spearman correlation tests. A p value of less than 0.05 was considered significant. Informed consent for blood sampling was sought and given by all patients for the purposes of this study.

\section{Results}

COAGULATION PROFILES

A total of $18(62 \%)$ patients had a deficiency of one or more of the natural anticoagulant proteins as defined by our normal ranges. Furthermore, values of anticoagulant proteins were towards the lower end of the normal range in most patients (fig 1). There were deficiencies of protein $\mathrm{C}$ and antithrombin in 12 patients $(41 \%)$ each and protein $S$ in 11 patients $(38 \%)$, with overlapping of deficiencies in several patients. Thus there were eight cases $(28 \%)$ of combined proteins $\mathrm{C}$ and $\mathrm{S}$ deficiency, nine cases $(31 \%)$ of protein $\mathrm{C}$ and antithrombin deficiency, seven cases $(24 \%)$ of protein S and antithrombin deficiency, and six cases $(21 \%)$ of combined deficiency of all three proteins. An increased PT ratio of at least 1.3 was present in 19 patients $(66 \%)$ and an increased APTT ratio of at least 1.2 was present in eight $(28 \%)$. There were significant positive correlations between concentrations of the different anticoagulant proteins in individual patients, and significant negative correlations with corresponding PT and APTT ratios, but no significant correlations with albumin concentrations. Table 1 summarises these data.
When natural anticoagulant concentrations in the different patient groups were compared, there were no consistently significant differences found between groups. However, there was a trend towards lower concentrations of each protein in group 2 compared with group 3; median protein $\mathrm{C}$ concentrations were 660 and $880 \mathrm{U} / \mathrm{dl}$ respectively $(\mathrm{p}=0.02$, MannWhitney U test), median protein $\mathrm{S}$ concentrations 660 and $750 \mathrm{U} / \mathrm{dl}$ respectively $(\mathrm{p}=0.12)$, and median antithrombin concentrations 690 and $840 \mathrm{U} / \mathrm{dl}$ respectively $(\mathrm{p}=0.06)$. When anticoagulant concentrations were analysed according to the presence or absence of additional mesenteric and/or splenic vein thrombosis in patients with extrahepatic PVT, no consistent differences or trends were found (data not shown).

In patients without overt myeloproliferative disease $(n=25)$ platelet counts were low in $19 / 25$ cases (median level $103 \times 10^{9} / 1$, range 20-322). Factor VII concentrations were measured in nine patients with increased PT ratios and were low in five cases (median level 490 U/dl, range 350-750). Fibrinogen concentrations were normal in all nine of these patients (median $2.9 \mathrm{~g} / \mathrm{l}$, range 1.8-4.2) and D-dimer concentrations were normal in all except two (concentrations 500 and 1000 $\mathrm{ng} / \mathrm{ml}$ respectively). Lupus anticoagulant and the factor $\mathrm{V}$ Leiden mutation were detected in one patient each and one further patient had APC resistance in the absence of the factor $V$ Leiden mutation. The prothrombin gene mutation was not found in any of the 10 patients tested. Two new cases of myeloproliferative disease (both essential thrombocythaemia) were diagnosed by bone marrow analysis at the time of presentation.

\section{FAMILY STUDIES}

Complete family studies of proteins C, S, and antithrombin concentrations for both parents of an index case of PVT with a deficiency of at least one of these proteins were available in nine cases. Figure 2 illustrates these data. All index cases had deficiency of at least one natural anticoagulant protein and some had combined deficiencies; in total there were six cases of protein C deficiency, three of protein S deficiency, and five of antithrombin deficiency. In contrast only three cases of natural anticoagulant protein deficiency were identified in corresponding parents: one had protein $\mathrm{C}$ deficiency and two had antithrombin deficiency. All were parents of different cases and all were associated with corresponding deficiency of the same protein as the index case (the family with protein $\mathrm{C}$ deficiency had a history of thromboembolic disease in other siblings).

When concentrations of natural anticoagulant proteins in all index cases and parents were compared, these were significantly lower in the index cases $(p<0.001$ for each of proteins $C, S$, and antithrombin, Mann-Whitney U test). As deficiency of natural anticoagulant proteins is usually inherited heterozygously, ${ }^{10}$ concentrations in index cases were also compared with whichever was the lower of the two corresponding values in parents. For protein $\mathrm{C}$ the median 


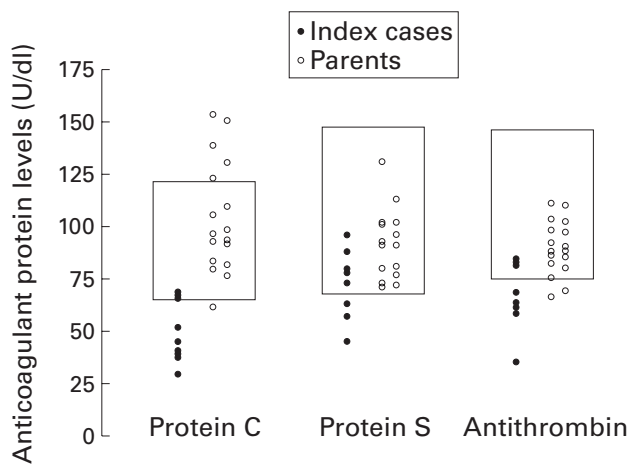

Figure 2 Scatterplot of protein $C$, $S$, and antithrombin concentrations in nine patients with portal vein thrombosis (index cases) and corresponding concentrations in parents. Comparison of concentrations in the index cases with the lower of the corresponding values in parents showed significantly lower concentrations in index cases (protein $C$, $p<0.01$; protein $S, p<0.05$; and antithrombin, $p<0.05$, Wilcoxon rank sum).

value in index cases expressed as a percentage of the lower of the corresponding values in parents was $55 \%$ (range $38-80 \%$, p $<0.01$, Wilcoxon rank sum); for protein $S$ the corresponding percentage was $72 \%$ (range $63-122 \%$, $\mathrm{p}<0.05)$; and for antithrombin the corresponding percentage was $78 \%$ (range $39-119 \%$, $\mathrm{p}<0.05)$.

\section{COAGULATION PROFILES IN SELECTED VENOUS BEDS}

Table 2 shows individual concentrations of proteins $\mathrm{C}, \mathrm{S}$, and antithrombin in hepatic and splenic veins, expressed as a percentage of synchronous peripheral vein concentrations in seven patients, together with mean concentrations from 15 patients with portal hypertension caused by parenchymal liver disease. Results were not uniformly consistent but hepatic vein concentrations of each of the natural anticoagulant proteins tended to be lower compared with peripheral vein concentrations $(p=0.27$, Wilcoxon rank sum). In contrast, splenic vein concentrations tended to be higher than peripheral vein concentrations $(p=0.14$, Wilcoxon rank sum). In patients with parenchymal liver disease, hepatic vein concentrations were

Table 2 Concentrations of proteins $C, S$, and antithrombin in different vascular beds

\begin{tabular}{|c|c|c|c|c|c|c|}
\hline \multirow[b]{2}{*}{ Patient } & \multicolumn{3}{|c|}{ Hepatic vein ${ }^{\star}$} & \multicolumn{3}{|c|}{ Splenic veint } \\
\hline & $P C$ & $P S$ & $A T$ & $P C$ & $P S$ & $A T$ \\
\hline 1 & 98 & 91 & - & & & \\
\hline 2 & 78 & 96 & 102 & & & \\
\hline 3 & 119 & 114 & 92 & & & \\
\hline 4 & 96 & 92 & 89 & & & \\
\hline 5 & & & & 106 & 118 & 102 \\
\hline 6 & & & & 82 & 100 & 140 \\
\hline 7 & & & & 95 & 126 & 107 \\
\hline Liver disease $\ddagger$ & 90 & 98 & 100 & & & \\
\hline
\end{tabular}

Concentrations of proteins $\mathrm{C}, \mathrm{S}$, and antithrombin measured in hepatic or splenic veins in individual patients with extrahepatic portal vein thrombosis (patients 1-3 and 5-7) or non-cirrhotic portal hypertension (patient 4), expressed as a percentage of concurrent peripheral vein levels. Patients 1-3 were sampled at the time of transjugular liver biopsy; patient 4 at the time of TIPSS insertion, and patients 5-7 at the time of splenorenal shunt surgery (all samples were taken prior to intervention).

$\ddagger$ Mean hepatic vein concentrations for 15 patients with intrinsic liver disease (mostly alcoholic cirrhosis) and portal hypertension (but without portal vein thrombosis) taken at the time of transjugular biopsy $(n=13)$ or TIPSS insertion $(n=2)$.

* Hepatic versus peripheral vein concentrations in PVT group $(p=0.27)$, and in liver disease group $(\mathrm{p}<0.01)$ (Wilcoxon rank sum).

†Splenic versus peripheral vein concentrations in PVT group ( $\mathrm{p}=0.14$, Wilcoxon rank sum).

PC, protein C; PS, protein S; AT, antithrombin.
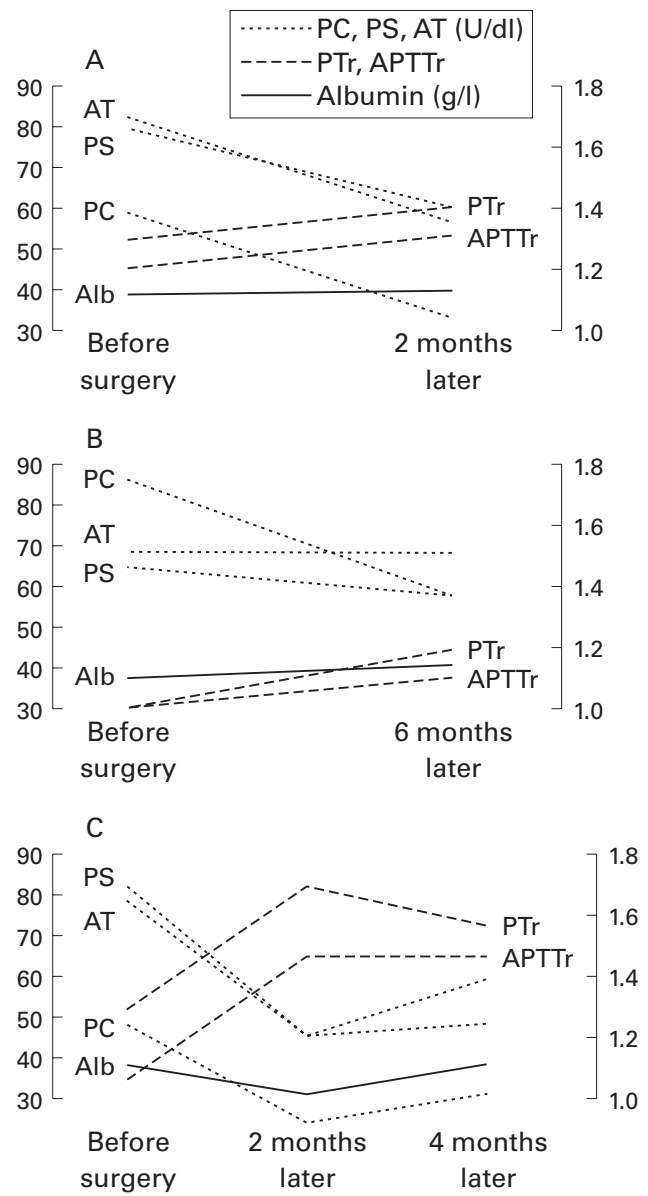

Figure 3 Levels of proteins $C$ (PC), $S$ (PS), antithrombin $(A T)$, and albumin, with prothrombin time $(P T)$ and activated thromboplastin time (APTT) ratios, before and after surgery in three patients undergoing splenorenal shunting (with preservation of the spleen) for portal vein thrombosis. (A) Patient 1, (B) patient 2, (C) patient 3.

lower than peripheral vein concentrations and in these patients more observations were available ( $p<0.01$, Wilcoxon rank sum).

COAGULATION PROFILES BEFORE AND AFTER PORTOSYSTEMIC SHUNTING

There were significant reductions in the concentrations of proteins $\mathrm{C}, \mathrm{S}$, and antithrombin postoperatively in each of the three patients who underwent splenorenal shunting ( $\mathrm{p}<0.05$, Wilcoxon rank sum) and corresponding significant increases in the PT and APTT ratios $(\mathrm{p}<0.05)$. In contrast the serum albumin level fell slightly in only one patient. There were no clinical complications postoperatively in any patient and none had been treated with anticoagulants. There was a trend towards subsequent "recovery" of these values in one patient in whom serial postoperative values were available. Figure 3 illustrates these cases.

\section{Discussion}

This study confirms that single or combined deficiencies of natural anticoagulant proteins are a common finding in PVT and suggests that the majority of deficiencies are acquired, presumably as a consequence of PVT, and not because of a hereditary genetic defect. How- 
ever, a minority of cases of PVT may have a true underlying hereditary anticoagulant protein deficiency and this can only be confirmed by careful investigation of family members, preferably including both parents. In this series a diagnosis of probable hereditary anticoagulant protein deficiency was made in three of nine cases investigated. An alternative way to make this diagnosis where parental studies are not possible might be by screening of siblings, which could be used for both diagnostic and counselling purposes. Lastly, recent usage of gene sequencing in the elucidation of anticoagulant protein gene mutations may now provide the potential to determine whether such anticoagulant deficiencies in PVT are truly primary or not. ${ }^{11}$

Many cases of PVT are associated with increased PT and APTT ratios, and the low factor VII concentrations we found in these patients indicates that these abnormalities are likely to be caused by true reductions in procoagulant proteins. The strong correlation of PT and APTT ratios with natural anticoagulant protein concentrations suggests that a similar mechanism may underlie both abnormalities, involving reduction in both procoagulant and anticoagulant proteins. This mechanism remains unclear but is probably multifactorial. Based on our own observations and those of others we propose two possible complementary mechanisms which are summarised in fig 4 . Firstly, reduction in liver blood flow following PVT probably leads to a degree of hepatic atrophy; we have noted that many patients with PVT have small livers on imaging. This would probably lead to reduced hepatic protein synthesis, perhaps more selectively for coagulation factors compared with albumin in most cases (in support of this we have also managed several patients with PVT excluded from this study who had reduced concentrations of albumin in addition to coagulation factors). Secondly, shunting of blood from the liver may in itself lead to reduced peripheral concentrations of coagulation proteins, possibly owing to clearance or consumption. While we and others did not find definitive evidence for disseminated intravascular coagulation in patients with PVT, ${ }^{12}$ others have nevertheless reported changes consistent with a mild and compensated consumption coagulopathy in PVT and in experimental models of portosystemic shunting. ${ }^{6}{ }^{13}$ Portosystemic shunting will clearly occur in most or all cases of PVT and will be increased following any subsequent surgical shunt procedure. Thus the further reduction in anticoagulant proteins that we and others have observed following shunt surgery may in part be a consequence of therapeutic shunting per se, although this may also reflect further reduction in hepatic blood flow. ${ }^{7}$

Our finding of a trend towards lower concentrations of anticoagulant proteins in hepatic veins compared with peripheral veins in patients with PVT or intrinsic liver disease with portal hypertension is contrary to the assumption that these proteins are produced exclusively within the liver. This finding also supports the possibility that these proteins may

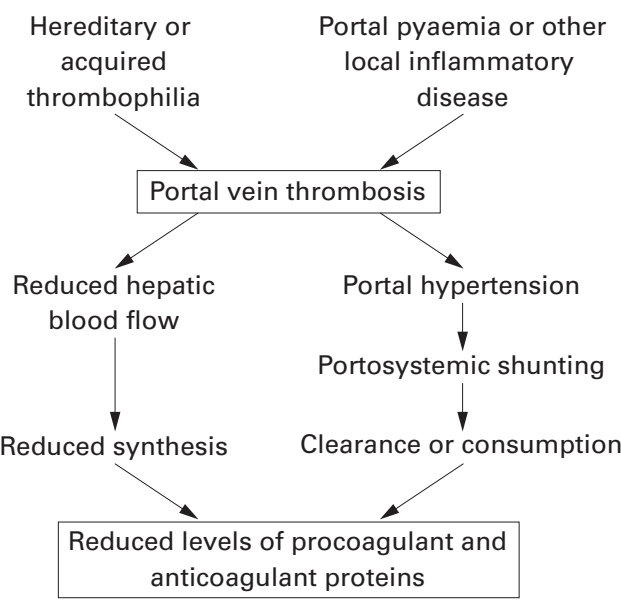

Figure 4 Proposed mechanism for reduction in concentrations of procoagulant and anticoagulant proteins in patients with portal vein thrombosis.

be cleared or consumed within the portal circulation in portal hypertension (whether caused by PVT or intrinsic liver disease), although this is difficult to ascertain in the absence of comparative data from healthy individuals. Furthermore, compensatory synthesis of these proteins occurs in other vascular beds including the spleen. ${ }^{14} 15$

Our case series also highlights some of the dilemmas in managing patients with PVT who have presented with variceal haemorrhage, and who may have an underlying thrombophilia state. Our usual practice is to eradicate oesophageal varices if these have bled, using adjunctive propranolol therapy to lower portal pressure. In cases of severe oesophageal or gastric variceal haemorrhage a portosytemic shunt may be chosen. Good long term results from either of these approaches have been reported by others. ${ }^{16}{ }^{17} \mathrm{~A}$ potential beneficial role for warfarin therapy in PVT remains debatable. We do not routinely warfarinise patients with PVT because of potential facilitation of variceal haemorrhage, although in our series some patients were warfarinised after shunt surgery because of associated myeloproliferative disease or previous shunt thrombosis in one case. In our experience it is rare for patients with PVT to develop clinically obvious extension of splanchnic thrombosis or any other thromboembolic disease. It is possible that the balance of coagulation abnormalities that frequently occur following PVT may favour reduction in any pre-existing thrombotic tendency. A recent retrospective case series did not show any significant alteration in outcome with warfarin therapy in PVT and further study is required before definite conclusions on the role of anticoagulation can be made. ${ }^{18}$

We are very grateful to fellow physicians and surgeons at the Liver Unit for allowing us to study patients under their care. We Liver Unit for allowing us to study patients under their care. We
are also very grateful to Dr S P Olliff, consultant radiologist, and to Mr J A C Buckels, consultant surgeon, for help in obtaining to Mr J A C Buckels, consultant
splanchnic vein blood samples.

1 Valla D, Denninger M, Delvigne J, et al. Portal vein thrombosis with ruptured oesophageal varices as presenting manifestation of

2 Valla D, Casedevall N, Huisse MG, et al. Etiology of portal vein thrombosis in adults. Gastroenterology 1988;94:10639. 
3 Levoir D, Emmerich J, Alhenc-Gelas M, et al. Portal vein thrombosis and factor V Arg 506 to Gln mutation. Thromb Haemost 1995;73:550-1.

4 Valla D, Chait Y, Denninger MH, et al. Portal and hepatic vein thromboses: concurrence of multiple prothrombotic states and focal factors. Hepatology 1997;26:203A.

5 Chamouard P, Pencreach E, Maloisel F, et al. Frequent factor II G20210A mutation in idiopathic portal vein thrombosis. Gastroenterology 1999;116:144-8.

6 Robson SC, Kahn D, Kruskal J, et al. Disorded hemostasis in extrahepatic portal hypertension. Hepatology 1993;18 $853-7$.

7 Dubuisson C, Boyer-Neumann C, Wolf M, et al. Protein C, protein $\mathrm{S}$ and antithrombin III in children with portal vein obstruction. F Hepatol 1997;27:132-5.

8 Willner IR, Waters B, Payton JD, et al. Hepatoportal sclerosis: clinical features and association with hypercoagulable states. Hepatology 1997;26:204A

9 Hillaire S, Degott C, Lebrec D, et al. Idiopathic noncirrhotic intrahepatic portal hypertension: a re-evaluation of aetiintrahepatic portal hypertension: a re-evaluaton

10 Lane DA, Mannucci PM, Bauer KA, et al. Inherited thrombophilia: part 2 (review article). Thromb Haemost $1996 ; 76: 824-34$
11 Aiach M, Borgel D, Gaussem P, et al. Protein C and S deficiencies (review article). Sem Haematol 1997;34:205-16.

12 Tran S, Yeo E, Heathcote EJ. Coagulation profile in non-cirrhotic portal vein thrombosis: evidence for ongoing thrombin generation. Hepatology 1997;26:395A.

13 Robson SC, Jaskiewicz K, Engelbrecht G, et al. Haemostatic and immunological sequelae of portacaval shunt in rats. Liver 1995;15:293-9.

14 Jamieson CS, McDowell SA, Marlar RA, et al. Developmental expression of protein $\mathrm{C}$ and protein $\mathrm{S}$ in the rat. Thromb Res 1995;78:407-19.

15 Tanabe S, Sugo T, Matsuda M. Synthesis of protein C in human umbilical vein endothelial cells. F Biochem 1991; 109:924-8.

16 Orloff $\mathrm{MH}$, Orloff MS, Rambotti M. Treatment of bleeding oesophageal varices due to extrahepatic portal hypertension: results of portal-systemic shunting during 35 years. F Paed Surg 1994;29:142-51.

17 Khan D, Krige E, Terblanche J, et al. A 15-year experience of injection sclerotherapy in adult patients with extraheof injection sclerotherapy in adult patients with extrahe-
patic portal venous obstruction. Ann Surg 1994;219:34-9.

18 Condat B, Pessione F, Erlinger S, Valla D. Portal vein thrombosis: outcome in 94 adult patients [abstract]. Hepatology 1997;26:204A 


\section{LETTERS TO THE EDITOR}

Differential expression of cyclooxygenase 2 in human colorectal cancer

EdiToR,-We were puzzled by the recent paper by Dimberg and colleagues (Gut 1999;45:730-732) which reported that upregulation of cyclooxygenase $2(\mathrm{COX}-2)$ protein expression was prominent in rectal adenocarcinomas compared with that in adenocarcinomas arising from the colon. "Low or undetectable levels of COX-2 protein expression" were demonstrated in 15 of 19 colonic adenocarcinomas located proximal to the rectum. Overall, upregulation of COX-2 protein expression was reported in only $56 \%$ of colorectal cancers.

Previous reports, ${ }^{1-7}$ which include one by the current authors on a not dissimilar case series ${ }^{1}$ and two in the joint authorship of the accompanying commentary writer, ${ }^{23}$ have shown consistent upregulation of COX-2 expression in colonic and rectal adenocarcinomas (in $85-90 \%$ of cases) compared with matched normal colonic mucosa using different techniques, including northern blot analysis, RT-PCR, western blot analysis, and immunohistochemistry. Furthermore, four of these studies refer to the distribution of adenocarcinomas throughout the colon without showing evidence of differential COX-2 expression between rectal and more proximal tumours. ${ }^{1245}$ In the one previous study which analysed COX-2 protein expression in human colorectal cancers by western blot analysis, ${ }^{7}$ immunoreactive COX-2 was detected in $76 \%$ of cases with a 10 -fold increase in median tissue COX-2 concentration compared with normal colonic mucosa.

In our view, the authors should attempt to explain the discrepancy between their results and previously published data. It is interesting to note that, in the study of Kargman et al, five of six patients taking NSAIDs had low or undetectable COX-2 protein expression. Moreover, aspirin has recently been shown to suppress induction of COX-2 mRNA and protein in interleukin- $1 \beta$ and phorbol ester stimulated human endothelial cells and fibroblasts. ${ }^{8}$ Do the authors have data on NSAID use in their cohort of patients prior to surgery?

M HULL

Division of Medicine and Molecular Medicine Unit, University of Leeds, Leeds, UK Email:medmah@stjames.leeds.ac.uk

M LANGMAN

University of Birmingham, Birmingham, UK

1 Dimberg J, Samuelsson A, Hugander A, et al. Gene expression of cyclooxygenase-2, group I and cytosolic phospholipase A2 in human colorectal cancer. Anticancer Res 1998;18:3283-7.

2 Eberhart CE, Coffey RJ, Radhika A, et al. Up-regulation of cyclooxygenase 2 gene expression in human colorectal adenomas and adenocarcinomas. Gastroenterology 1994;107:1183-8.

3 Shattuck-Brandt RL, Lamps LW, Heppner Goss KJ, et al. Differential expression of matrilysin and cyclooxygenase- 2 in intestinal and colorectal neoplasms. Mol Carcinog 1999;24: 177-87.

4 Gustafson-Svard C, Lilja I, Hallbook O, et al. Cyclooxygenase- 1 and cyclooxygenase- 2 gene expression in human colorectal adenocarcinomas and in azoxymethane induced coloni tumours in rats. Gut 1996;38:79-84.
5 Maekawa M, Sugano K, Sano H, et al. Increased expression of cyclooxygenase- 2 to -1 in human colorectal cancers and adenomas, but not in hyperplastic polyps. Jpn f Clin Oncol 1998;28: 421-6.

6 Sano H, Kawahito Y, Wilder RL, et al. Expression of cyclooxygenase-1 and -2 in human colorectal cancer. Cancer Res 1995;55: 3785-9.

7 Kargman SL, O'Neill GP, Vickers PJ, et al. Expression of prostaglandin $\mathrm{G} / \mathrm{H}$ synthase-1 and -2 protein in human colon cancer. Cancer Res 1995;55:2556-9.

8 Xu X-M, Sansores-Garcia L, Chen X-M, et al. Suppression of inducible cyclooxygenase 2 gene transcription by aspirin and sodium salicylate. Proc Natl Acad Sci USA 1999;96: 5292-7.

\section{Reply}

EdiToR,-We agree with Drs Hull and Langman that we found upregulation of COX-2 protein expression in a lower fraction of colorectal cancers (CRC) than previously reported. In part, this may simply be explained by the composition of different tumour types within $\mathrm{CRC}$ - that is, the number of colonic versus rectal tumours in our cohort compared with others. In the papers referred to it is difficult to assess the fraction of the different tumour types studied. The differences may also be dependent on the genetic basis for the CRCs studied, which we also have indicated in our report but perhaps not emphasised sufficiently. CRCs with a defective mismatch repair capability, recognised by microsatellite instability (MSI), are accompanied by reduced COX-2 levels. ${ }^{1}$ At present, we do not know the fraction of MSI type tumours in our series and therefore cannot assess this possibility. An indirect estimate may be achieved since the Min mouse model and human studies provide direct evidence that COX-2 expression may be related to loss of APC function. ${ }^{2}$ APC and $\beta$-catenin mutation analysis of our tumour series shows a good, although not perfect, correlation with COX-2 protein upregulation. Among 18/20 rectal tumours with COX-2 protein upregulation, 12 contained mutations in the APC/ $\beta$ catenin genes. In contrast, only one of three $\mathrm{APC} / \beta$-catenin mutated colon tumours revealed COX-2 protein induction and among the remaining 15 non-mutated tumours, two displayed COX-2 protein upregulation. Thus the fraction of $\mathrm{APC} / \beta$-catenin mutated tumours was also slightly lower (21/38-55\%) than previously reported and in accordance with the differential COX-2 induction observed. This may indicate that a larger fraction of CRCs in our cohort are of the MSI type.

Other possibilities for the differences in the fraction of COX-2 upregulation in our tumour series may be the definition of "induction". In our case, a tumour/normal ratio from densitometric scanning of western blots must exceed 2 in two successive independent experiments of the same sample pair to be considered true induction. The use of different methodologies may also influence relative expression of $\mathrm{COX}-2$, for example RT-PCR is sensitive to the quality of isolated mRNA and PCR is not really a quantitative method but needs to be carefully controlled to allow quantitative estimations.

It is also correct, as stated by Drs Hull and Langman, that NSAIDs may suppress COX-2 mRNA induction and COX-2 protein expression in some of the patients in our series. Normally, all drug treatments are withdrawn at least one week prior to surgery at our hospital, making most patients drug free at the time of surgery. However, we do not know if patients self-administer these types of drugs during the waiting period. We have reviewed the medical records for all CRCs included in the study and found that $7 / 39$ patients were receiving aspirin for cardiovascular protection. Five of these patients had rectal tumours and displayed 7-40-fold induction of COX-2 protein: the two patients with colonic cancer and aspirin treatment revealed $<2$ - and 10 -fold induction, respectively. Thus COX-2 suppression caused by NSAID cannot explain the low prevalence of COX-2 induction in the colonic tumours.

Regulation of COX-2 is not fully understood. Because of the close correlation of upregulated COX-2 with mutations in APC/ $\beta$-catenin genes it has been hypothesised that there is a regulatory link and that the chemopreventive effect of NSAIDs can be attributed to inhibition of COX-2. However, in a recent paper by $\mathrm{He}$ and colleagues ${ }^{3}$ it was demonstrated that PPAR $\delta$ (peroxisome proliferator activated receptor $\delta$ ) is a target of both APC and NSAIDs resulting in suppressed PPAR $\delta$ activity and promotion of apoptosis. In addition, COX-2 null mouse embryo fibroblast cells remain sensitive to the antiproliferative and antineoplastic effects of NSAIDs $^{4}$; hence there seems to be other important mechanisms for NSAID mediated tumour suppression.

The samples in our series were obtained consecutively without any selection. At present, we believe that the observed differential expression of COX-2 may be due to underlying differences in genetic alterations and/or that rectal tumours may represent a biologically distinct subtype of bowel cancer. However, we cannot exclude the possibility that the next 39 CRCs collected will display the opposite COX-2 expression pattern, although we believe this is unlikely.

J DIMBERG Department of Natural Science and Biomedicine, University College of Surgery, Faculty of Health Sciences, fönköping, Sweden Email:dija@hhj.hj.se P SÖDERKVIST Department of Biomedicine and Division of Cell Biology, Faculty of Health Sciences, Linköping, Sweden Email:petso@mcb.liu.se

1 Karnes WE, Shattuck-Brandt R, Burgart LJ, et al. Reduced COX-2 protein in colorectal cancer with defective mismatch repair. Cancer Res 1998;58:5473-7.

2 Oshima M, Dinchuk JE, Kargman SL, et al. Suppression of intestinal polyposis in $\mathrm{Apc}^{716}$ knockout mice by inhibition of cyclooxygenase 2 (COX-2). Cell 1996;87:803-9.

$3 \mathrm{He}$ TC, Chan TA, Vogelstein B, et al. PPAR $\delta$ is an APC-regulated target of nonsteroidal antian APC-regulated target of nonsteroidal

4 Zhang X, Morham SG, Langenbach R, et al. Malignant transformation and antineoplastic actions of nonsteroidal anti-inflammatory drugs (NSAIDs) on cyclooxygenase-null embryo fibroblasts. F Exp Med 1999;190:451-60.

\section{Proton pump inhibitors for Barrett's} oesophagus

Editor,- - Recently, the authors of two leading articles, Triadafilopoulos (Gut 2000; 46:144-46) and Shepherd (Gut $2000 ; 46: 147-49)$ referred to our paper in Gut. ${ }^{1}$ We would like to draw attention to the fact that the legend in tables 4 and 5 in our paper should be read as (cm.month), (squares.month), and (\%.month) since the variable is the area under the curve (AUC), which is the product of length or surface and 
time. The printed notation (with a slash) might suggest that the figures concern the change per month. In spite of our suggested change in the galley proof, this notation was maintained. Nevertheless, it does not change the purport of our conclusion, nor the discussion in both leading articles.

F T M PETERS

Department of Gastroenterology and Hepatology, Groningen University Hospital, PO Box 30 001, 9700 RB Groningen, The Netherland Email:ftm.peters@int.azg.nl

1 Peters FTM, Ganesh S, Kuipers EJ, et al. Endoscopic regression of Barrett's oesophagus double blind study. Gut 1999;45:489-494.

\section{MCP-3 in inflammatory bowel disease}

EDITOR,-We read with interest the article by Wedemeyer and colleagues (Gut 1999; 44:629-35) on chemokines in inflammatory bowel disease.

Monocyte chemotactic protein 3 (MCP-3) expression in inflammatory bowel diseases is a very interesting observation and we agree with the authors that MCP-3 might play an important role in the pathophysiology of these diseases.

We have recently published an article on the C-X-C chemokines interleukin (IL)-8 and IP-10, and the C-C chemokines MCP-1 and MCP-3 in the mucosa of active ulcerative colitis. ${ }^{1}$ It concerns an immunohistochemica study in which we showed increased expression of these chemokines in the lamina propria of patients with ulcerative colitis compared with normal controls. Furthermore, we observed a significant difference in expression between inactive and moderate/ severe ulcerative colitis based on the histological grading in MCP-1, MCP-3, and IL-8.

Wedemeyer and colleagues state in their discussion that MCP-1 is expressed in the epithelial cells and lamina propria whereas MCP-3 is almost exclusively produced by epithelial cells. However, in the results section and further in the discussion the authors mentioned sporadic MCP-3 expression in the lamina propria of inflamed tissue. The photographs show only epithelial cells and it is not possible to see the staining pattern of the lamina propria.

We found MCP-3 expressing cells in the lamina propria which was significantly increased in active ulcerative colitis compared with both inactive ulcerative colitis and normal controls. Furthermore, MCP-3 expression in lamina propria was also enhanced in patients suffering from pouchitis compared with patients with a normal pouch (unpublished data).

In the study of Wedemeyer et al, unfortunately the data on MCP-3 expression in Crohn's disease were not significant which might be because of the small number of patients examined. It would be interesting to further evaluate the role of chemokines in Crohn's disease.

In conclusion, albeit with some minor differences, both studies have shown that MCP-3 plays an important role in ulcerative colitis.

U HELWIG K M LAMMERS P GIONCHETTI

F RIZZELLO

$M$ CAMPIERI

Department of Internal Medicine and Gastroenterology, University of Bologna, Bologna, Italy Email:paolo@meol.unibo.it
M UGUCCIONI Theodor Kocher Institute, University of Bern, Bern, Switzerland

1 Uguccioni M, Gionchetti P, Robbiani DF, et al. Increased expression of IP-10, IL-8, MCP-1 and MCP-3 in ulcerative colitis. Am $\mathcal{F}$ Pathol 1999;155:331-6.

\section{Reply}

Editor,-We thank Dr Helwig and colleagues for their interest in our recent paper in which we showed enhanced expression of the C-C chemokine MCP-3 in inflammatory bowel disease mucosa. In the article by Uguccioni and colleagues, ${ }^{1}$ we noted their slightly different findings in terms of localisation of MCP-3 expression. Using different techniques (cryostat and paraformaldehyde fixatives, different anti-MCP-3 antibodies) we found consistent expression of MCP-3 in the intestinal epithelium and sporadically in the lamina propria. Uguccioni et al reported MCP-3 expression in the lamina propria. The reason why they did not find MCP-3 expression in the epithelium remains unclear. A possible explanation could be that patients received different therapies at the time of colonoscopy. Only one of the patients investigated in the study by Uguccioni et al received steroids while most patients with macroscopic inflamed mucosa enrolled in our study received either oral or parenteral steroid medication at the time of biopsy. As mentioned in the results, we also found occasional MCP-3 staining cells within the lamina propria but did not focus our investigation on these cells. Which lamina propria cells express MCP-3 remains to be determined. We found that human isolated mast cells are capable of expressing MCP-3 mRNA (unpublished data) which makes them a possible candidate. Other candidates are macrophages and endothelial cells, as reported by Ying and colleagues, ${ }^{2}$ who found MCP-3 expression in bronchial biopsies located in these two cell types and in epithelial cells.

In conclusion, we agree with Dr Helwig and colleagues that the role of chemokines in inflammatory bowel disease needs to be evaluated in more detail. Further data are necessary to answer the question of whether or not these alterations in chemokine expression are restricted to specific disorders such as ulcerative colitis or resemble a more general finding associated with any type of intestinal inflammation and host defence mechanisms.

J WEDEMEYER A LORENTZ M P MANNS $S \mathrm{C}$ BISCHOFF

Department of Gastroenterology and Hepatology, Medical School of Hannover, Hannover, Germany Email: bischoff.stephan@mh-hannover.de

1 Uguccioni M, Gionchetti P, Robbiani DF, et al. Increased expression of IP-10, IL-8, MCP-1
and MCP-3 in ulcerative colitis. Am $\mathcal{f}$ Pathol and MCP-3 in ulce

2 Ying S, Meng Q, Zeibecoglou K, et al. Eosinophil chemotactic chemokines (eotaxin, eotaxin-2, RANTES, monocyte chemoattractant protein-3 (MCP-3), and MCP-4), and C-C chemokine receptor 3 expression in bronchial biopsies from atopic and nonatopic (intrinsic) asthmatics. F Immunol 1999;163:6321-9.

One minute unbuffered urease test: should it be read at 10 minutes?

EDITOR,- - The one minute unbuffered rapid urease test, ${ }^{1}$ previously described in your journal, ${ }^{2}$ was adopted for use at the Royal Melbourne Hospital endoscopy day ward because of its affordability, ease of use, and rapidity. Over time, we had noticed a number of cases where the test had been negative at the one minute mark but later became positive. As we were unsure of whether these "late" positive results represented true or false positives, we decided to run a short study to assess the accuracy of the urease test compared with the "gold standard" of histology.

To this end we read and recorded the urease test at one and 10 minutes and compared the results with histological demonstration of Helicobacter pylori on a single antral biopsy. This was carried out on 90 unselected patients undergoing upper gastrointestinal endoscopy for varied indications. Forty one patients were found to have $H$ pylori on histology. The urease test was positive in 20 of these 41 when read at one minute compared with 34 at 10 minutes. There were two false positive results at the one minute mark and four at the 10 minute mark. The performance of the urease test at one and 10 minutes is compared in table 1 .

We have demonstrated a significant disparity from published data ${ }^{2}$ in the sensitivity of the ultra rapid urease test in our ward. Previous reports have shown a difference between the test results at one minute compared with 15 minutes but this was attributed to the lower initial temperature of the test solution as it was kept refrigerated until just prior to use. ${ }^{3}$ In our ward the test solution is made up in batches and stored at $4^{\circ} \mathrm{C}$ in the refrigerator but the test tubes are put out at the beginning of the day and thus start off at room temperature. There is evidence to suggest that storage at $4^{\circ} \mathrm{C}$ for a number of days has no deleterious effects on the performance of the rapid urease test $^{3}$ but this factor may explain the poor performance of the one minute test in our hands.

These factors aside, it is important to point out that we have concluded that the rapid urease test is quite accurate, with sensitivity and specificity comparable with published values $^{4-6}$ for other urease tests, if the reading time is modified to 10 minutes. There are other instances ${ }^{3}{ }^{4}$ of variability of urease test performance depending on the time interval at which it is read. It may be that, prior to use, these tests need to be validated as conditions may vary from the prescribed ones under which the test was designed.

At 10 minutes the unbuffered urease test still provides results quicker than most rapid urease tests and in fact allows us to inform patients and organise further management for them prior to discharge from the endoscopy suite. Given the overall performance of the test, we are quite happy to plan the treatment of $H$ pylori on the basis of its results. Histology can be reserved for those cases where urease testing is equivocal or other signs, such as mucosal abnormalities, are being sought.

S SENGUPTA G CROSTHWAITE University Department of Surgery, Royal Melbourne Hospital, Parkville 3050, Australia

Table 1 Comparison of the unbuffered rapid urease test performance at one and 10 minutes

\begin{tabular}{lllc}
\hline & $\begin{array}{l}1 \text { min } \\
\text { test }\end{array}$ & $\begin{array}{l}10 \text { min } \\
\text { test }\end{array}$ & p Value \\
\hline Sensitivity & $49 \%$ & $83 \%$ & $<0.001$ \\
Specificity & $96 \%$ & $92 \%$ & 0.20 \\
Positive predictive value & $91 \%$ & $90 \%$ & 0.43 \\
Negative predictive value & $69 \%$ & $87 \%$ & $<0.002$ \\
\hline
\end{tabular}


Correspondence to: G Crosthwaite, 1st Floor, 55 Flemington Rd, North Melbourne 3051, Australia. Email: g.1.crosthwaite@bigpond.com

1 Arvind AS, Cook RS, Tabaqchali S, Farthing MJG. One-minute endoscopy room test fo Campylobacter pylori. Lancet 1988;i:704.

2 Thillainayagam AV, Arvind AS, Cook RS, Harrison IG, Tabaqchali S, Farthing MJG. Diagnostic efficiency of an ultrarapid endoscopy room test for H pylori. Gut 1990;32:467-9.

3 NG FH, Wong SY, NG WF. Storage temperature of the unbuffered rapid urease test. $A m \mathcal{F}$ Gastroenterol 1997;92:2230-1.

4 Yousfi MM, El-Zimaity HM, Cole RA, Genta RM, Graham DY. Comparison of agar gel (CLOtest) or reagent strip (PyloriTek) rapid urease tests for detection of (PyloriTek) rapid Am f Gastroenterol 1997:92:997-9.

5 Cutler AF. Testing for H. pylori in clinical pracCutler AF. Testing for H. pylori in
tice. Am $\mathcal{f}$ Med 1996;100:35-41S.

6 tice. Am 7 Med 1996;100:35-41S. Weston AP, Campbell DR, Hassanein RS,
Cherian R, Dixon A, McGregor DH. Prospective, multivariate evaluation of CLOtest performance. Am $\mathcal{F}$ Gastroenterol 1997;92:1310-15.

\section{Thalidomide treatment of oesophageal ulceration}

EDITOR,-I read with interest the case report of oesophageal ulceration treated successfully with thalidomide (Gut 1999;45:463-464). With others, I reported the first successful use of this drug in oesophageal ulceration in $1992^{1}$ although the patient we reported on did indeed have AIDS, and the ulceration was diffuse and proliferative rather than discrete, mimicking lymphoma both macroscopically and microscopically.

The precise mechanism of thalidomide's effectiveness in oesophageal ulceration remains unclear. The case reported raises the intriguing possibility of more widespread application of this drug in idiopathic gastrointestinal ulceration. It has already been used in the lower gastrointestinal tract in Crohn's disease with some success. Idiopathic aphthous ulceration may be the first step in the pathogenesis of Crohn's disease-the breach in the mucosal barrier may allow entry of bacterial flora and their products to the internal milieu thus setting in train the inflammatory cascade that becomes clinical inflammatory bowel disease. A potent, orally available, and especially non-teratogenic $\mathrm{T}$ cell inhibitor as effective as thalidomide would be a useful addition to the pharmacological weaponry available for use in inflammatory bowel disease and perhaps also in helicobacter negative gastroduodenal and small intestinal ulceration.

J RYAN

Brighton Gastroenterology Associates, Suite 5, 2 Church St, Brighton 3186, Victoria, Australia

Email:jeremy@brightongastro.com

1 Ryan J, Colman J, Pedersen J, Benson E. Thalidomide to treat esophageal ulcer in AIDS. New Engl f Med 1992;327:208.

\section{Use of Doppler ultrasound in Crohn's disease}

EDITOR,-We read with interest the article by Maconi et al (Gut 1998;43:654-650). We find it encouraging that other workers are interested in superior mesenteric artery (SMA) flow concerning Crohn's disease activity. Our group has been working on the subject for several years. However, we found it surprising to read that "according to the literature" SMA flow does not correlate with disease activity. Firstly, disease activity needs to be defined. The Crohn's disease activity index does not correlate with disease activity in individual patients ${ }^{12}$ and the reference standard used by Maconi et al is probably not a reliable indicator for disease activity. Secondly, it is not correct in our view to correlate the resistive index in one article ${ }^{3}$ with mean velocity in another ${ }^{4}$ and flow volume in yet another, ${ }^{56}$ and make the statement "yielding conflicting results" on page 654 . In our opinion only flow volume measurements can be used as a reliable indicator. ${ }^{58}$ The fact that Maconi et al did not find a correlation between SMA volume flow and disease activity is probably caused by their choice of reference standard, as pointed out by Kjeldsen and colleagues, ${ }^{1}$ Hodgson and Bhatti, ${ }^{2}$ and van Oostayen and colleagues. ${ }^{5}$

J A VAN OOSTAYEN M N J M WASSER Leiden University Medical Centre, Department of Diagnostic Radiology, Bldg I, C2-S, Albinusdreef 2, 2333 ZA, Leiden, Netherlands

1 Kjeldsen J, Schaffalitzky de Muckadell OB. Assessment of disease severity and activity in inflammatory bowel disease. Scand f Gastroen terol 1993;28:1-9.

2 Hodgson HJF, Bhatti M. Assessment of disease activity in ulcerative colitis and Crohn's disactivity in ulcerative colitis and Crohn'

3 Bolondi L, Gaiani S, Brignola C, et al. Changes in splanchnic hemodynamics in inflammatory bowel disease. Non-invasive assessment by Doppler ultrasound flowmetry. Scand $\mathcal{F}$ Gastroenterol 1992;27:501-7.

4 Maconi G, Imbesi V, Bianchi Porro G. Doppler ultrasound measurement of intestinal blood flow in inflammatoty bowel disease. Scand $\mathcal{F}$ Gastroenterol 1996;31:950-3.

5 Van Oostayen JA, Wasser MNJM, Griffioen G et al. Doppler sonography evaluation of superior mesenteric artery flow to assess Crohn's disease activity: correlation with clinical evaluation, Crohn's disease activity index, and $\alpha_{1}$-antitrypsin clearance in feces $A f R$, $m$ ( Roentgenol 1997;168:429-33.

6 Hare C, Hassan MT, Bartram CI, et al. Superior mesenteric artery Doppler flow: a valuable mesenteric artery Doppler flow: a valuable
indicator of disease activity in Crohn's disease. Gut 1996:38:A639 (abstract).

7 Van Oostayen JA, Wasser MNJM, Van Hogezand RA, Griffioen G, De Roos A. Activity of zand RA, Griffioen G, De Roos A. Activity of
Crohn disease assessed by measurement of Crohn disease assessed by measurement of superior mesenteric artery flow
US. Radiology 1994;193:551-4.

8 Van Oostayen JA, Wasser MNJM, Griffioen G, Van Hogezand RA, C.B.H.W.L, De Roos A Diagnosis of Crohn's ileitis and monitoring of disease activity: value of Doppler ultrasound of superior mesenteric artery flow. Am $\mathcal{F}$ Gastroenterol 1998;93:88-91.

Percutaneous drainage of echinococcal cysts (PAIR-puncture, aspiration, injection, reaspiration): results of a worldwide survey for assessment of its safety and efficacy

EDITOR,-In 1996 a letter (Gut 1996;38:936) about the use of PAIR (puncture, aspiration, injection of a scolecidal agent, reaspiration) raised a criticism of Dr Morris, a leading expert on the treatment of echinococcosis. ${ }^{1}$
At the same time the WHO Informal Working Group on Echinococcosis launched a survey to evaluate the status of this procedure. A number of centres around the world known to be active in this field were requested to complete forms for patients treated with PAIR: 765 abdominal cysts, mostly hepatic, treated with this technique were reported from various countries. We report the results of this survey (table 1 ).

Either needles (18-22 gauge) or catheters (5-9 French gauge), depending on the size and location of the cysts, were used. Scolecidal agents were mainly $20 \%$ hypertonic saline and $95 \%$ ethanol solution. After aspiration and parasitological control of the fluid, a quantity of scolecidal agent, approximately equivalent to one third of the amount aspirated, was injected into the cysts and left for a time varying from 5 to 30 minutes, and then reaspirated: only in the cases of Giorgio and colleagues ${ }^{2}$ was the scolecidal agent not reaspirated. In all cases, except for two failures $(0.26 \%)$ followed by surgery, various degrees of reduction in size (at least $50 \%$ ) and involution (healing) of the cysts were observed on ultrasound follow up. Anaphylactic shock occurred in four cases $(0.52 \%)$ and was promptly treated; in one case $(0.13 \%)$ death ensued notwithstanding resuscitative manoeuvres. Recurrences were observed in 12 cases $(1.57 \%)$ but in eight $(1.05 \%)$ they were related to an insufficient amount of scolecidal agent (one tenth instead of the average equivalent of one third of the aspirated fluid). Spillage of the fluid in the abdominal cavity was observed in four cases $(0.52 \%)$ but all patients were receiving prophylaxis with albendazole (seven days to four hours before to 1-4 weeks after) and no peritoneal dissemination occurred. Minor complications (fever, rash, abscess formation, and biliary fistules) were observed in 105 cases $(13.7 \%)$; abscess formation was treated with echo guided percutaneous drainage. The follow up is more than five years for 75 cases at the time of presentation of this survey.

These data show that the use of PAIR is widespread and increasing, especially in countries where echinococcosis is endemic. This is also because of its low cost and high efficacy. These data are in accordance with the literature: as of today more than 2400 cysts have been punctured and reported in indexed journals, and success and complication rates are even lower than those of our survey. PAIR is a safe and effective therapeutic tool; the risk of anaphylaxis during PAIR has been greatly overrated. Complication rates, recurrences, and mortality rates are lower than those of surgery. ${ }^{3}$ Accuracy of follow up may be a problem where the population is nomadic, but so far no case of peritoneal dissemination after PAIR has been reported.

Table 1 Results of the survey on PAIR by the WHO Informal Working Group on Echinococcosis

Total cases (cysts)
Follow up $>5$ y
Follow up $<5$ y
Major complications
Anaphylactic shock
Spillage
Minor complications
Fever (33), rash (14), pain (30), infection of
cavity (11), nausea and vomiting (10), intracystic
haemorrhage (3), hypotension (2)
Failures
Recurrences

765

75
690

$4(0.52 \%)$ (1 death- $0.13 \%)$

$4(0.52 \%)$ (albendazole prophylaxis)

$105(13.7 \%)$

$2(0.26 \%)$

$12(1.57 \%)(8(1.05 \%)$ due to an insufficient quantity of scolicide) 
There is a need for further studies on PAIR. One of the main issues is to standardise at least some of the points of the various PAIR protocols, under the supervision of the WHO, to compare their efficacy, set up prospective studies, and distribute guidelines to optimise the use of the treatment. Whereas before we felt that the technique was limited to a narrow group of patients, ${ }^{4}$ today we believe that PAIR is not only an alternative but an effective first choice diagnostic and therapeutic tool in the management of human cystic echinococcosis.

C FİLICE

E BRUNETTI

R BRUNO

WHO-INFORMAL WORKING GROUP ON ECHINOCOCCOSIS-PAIR NETWORK† Divisione di Malattie Infettive e Tropicali, IRCCS Policlinico S Matteo, Università di Pavia, via Taramelli 5, 27100, Pavia, Italy

Correspondence to: E Brunetti.

Email:selim@unipv.it

†D Vuitton, Besançon, France; P Schantz, Atlanta, USA; M Caremani, Arezzo, Italy; A Giorgio, Napoli, Italy; C Bastid, Marseille, France; J Napaniak, Poznan, Poland; E Zeyhle, Nairobi, Stefaniak, Poznan, Poland; E Zeyhle, Nairobi,
Kenya; H Wen, China; V Pelaez, Neuquèn, Kenya; H Wen, China; V Pelaez, Neuquen, Argentina; R Pettinari, Chubut, Argentina;
Akhan, Ankara, Turkey; S Men, Ankara, Turkey; G Hernandez, Avila, Spain; H Schipper, Amsterdam, Netherlands.

1 Morris DL. Percutaneous aspiration in the treatment of hydatid liver cysts. Gut 1996;38:936.

2 Giorgio A, Tarantino L, Francica G, et al. Unilocular hydatid liver cysts: treatment with US-guided, double percutaneous aspiration and alcohol injection. Radiology 1992;184:70510.

3 Khuroo MS, Wani NA, Javid G, et al. Percutaneous drainage compared with surgery for hepatic hydatid cysts. $N$ Engl f Med 1997;337: 881-7.

4 Filice C, Brunetti E. Echo-guided diagnosis and treatment of hepatic hydatid cysts. Clin Infect Dis 1997;25:169-71.

\section{Reply}

EDITOR,-I remain unconvinced of two basic things: is it (PAIR) safe and is it effective? With regard to safety these are three issues.

(a) Anaphylaxis. This occurred in four patients after PAIR in the current report and caused one death. An additional three patients became hypotensive and 14 developed a rash. I believe this is a higher risk than surgery should entail.

(b) Dissemination. The peritoneal dissemination of hydatid disease due to needling a liver cyst will take some time to present-how long? In a series of patients with peritoneal hydatid disease, presentation did not occur until nine years (5-14 years) after surgery. ${ }^{1}$ Current follow up of PAIR does not address this issue. Spillage of hydatid material only causes recurrence in approximately $30 \%$ of patients. ${ }^{2}$ Peritoneal hydatid can be a serious or fatal problem.

(c) Sclerosing cholangitis. A significant proportion of hydatid cysts communicate with the biliary tree; use of scolicidal agents even at open surgery has caused sclerosing cholangitis. The surgeon has the opportunity of identifying and protecting such a communication prior to the use of scolicide.

Is it effective? The comment that the recurrence rate of PAIR is now less than sur- gery is either simplistic or deliberately misleading. Filice et al state that 75 patients (or is it cysts?) have been followed up for five years-the type and frequency of follow up is not stated and this is really critical. Careful ultrasonic follow up can demonstrate recurrence following surgery in up to $22 \%$ of patients ${ }^{3}$ but one can equally well quote surgical series with poor follow up with low recurrence rates; to claim that recurrence rates are lower following PAIR when the type and completeness of follow up is not even stated in scientifically quite invalid.

That cysts shrink (variably) following PAIR is reported, but what does this mean - is this synonymous with parasite death? I doubt it! Only one PAIR study reported reaspiration at three days post-PAIR ${ }^{4}$ and $2 / 14$ patients had live proloscolices.

The use of albendazole for four hours to seven days prior to and for 1-4 weeks after PAIR is clearly an attempt to reduce the risk of recurrence. In my original laboratory work it took of the order of 30 days to be effective ${ }^{5}$ and in humans, two patients who received albendazole for one and three weeks, respectively, prior to operation had viable proloscolices. $^{6}$ The use of post-spillage therapy to reduce the risk of implantation has been variably effective in animal models of spillage. $^{78}$

We have made at least some attempt to define the minimum length of such therapy. ${ }^{8}$

The over representation of a poor presentation of data, which I suspect is of even poorer quality, does not improve my view of PAIR, or of the WHO working group. I am quite prepared to accept that PAIR may be the best available option in some areas of the world where surgery and perioperative care are compromised by economic factors or lack of experience, but its comparison with surgery should await careful long term follow up. Department of Surgery St George Hospital, University of New South Wales, Kogarah 2217, Australia

Correspondence to: Professor D Morris.

Email: David.Morris@unsw.edu.au

1 Koravias DD, Vagianos CE, Kakkos SK, Panagopoulos CM, Andrcula K. Peritonal echinococcosis. World f Surg 1996;20:337-40.

2 Schiller CF. Complications of echinococcus cyst rapture. A study of 30 cases. $\mathcal{F A M A} 1966 ; 195$ : 220-2.

3 Little JM, Hollands MT, Eckberg H. Recurrence of hydatid disease. World F Surg 1988;12: 700-4.

4 Giorgio A, Tarantino L, Francica G, et al. Unilocular hydatid liver cysts: treatment with US-guided, double percutaneous aspiration and alcohol injection. Radiology 1992;184:70510 .

5 Chinnery JB, Morris DL. Effect of albendazole sulphoxide on viability of hydatid protosceleces in vitro. Trans $R$ Soc Trop Med Hyg 1986;80: 815-17.

6 Morris DL. Preoperative albendazole therapy in hydatid cyst. Br F Surg 1987;74:805-6

7 Morris DL, Chinnery J, Hardcastle JD. Can albendazole reduce the risk of implantation of spilled protoscoleces? An animal study. Trans $R$ Soc Trop Med Hyg 1986;80:481-4.

8 Taylor DH, Morris DL, Richards KS. Perioperative prophylactic chemotherapy of echinococcus granulosus: Determination of minimucciniin vitro protoscolex culture. HPB Surgery in vitro protoscolex culture. HPB Surgery
$1990 ; 2: 159-64$.
BOOK REVIEWS

Mucosal T cells. Chemical Immunology. Vol 71. Edited by MacDonald TT. (Pp 242; illustrated; individuals $\$ 104.50$, institutions \$208.75.) Switzerland: Karger, 1998. ISBN 3805567227 .

I should say immediately that this is an excellent book. For those interested in mucosal immunology, little more is necessary. It comprises an up to date and comprehensive series of 13 reviews by scientists who have made important contributions to the field. I am very pleased to have a copy; it will be extremely useful.

Clinical gastroenterologists spend a great deal of their time battling with mucosal $\mathrm{T}$ cells, yet because these cells are too small to be seen with an endoscope (in any case they would be obscured in exudate or by the epithelial cell layer) and are difficult to stain on formalin fixed histopathology sections, they are rarely observed. The weapons used against these adversaries are principally nonspecific drugs which have, obviously, worked if the patient gets better.

Thus, although it is tempting to take Sherlock Holmes' attitude and, when told by Watson that the earth revolves around the sun, feel that the mind is an attic that when filled with details of astronomy (or mucosal immunology), will leave no space for the more useful minutiae of Egyptian tobacco (or the indications for the latest biliary expanding metal stent). But Holmes liked to have a comprehensive grasp of the background of the case, and I believe that he would not have missed a chance to study this book had he been a contemporary gastroenterologist.

The language of the book may be a problem for the non-immunologist, particularly if one's medical school notes stop at the Bursa of Fabricius. This is certainly state of the art immunology, but is directed at clinicians as well as scientists. Therefore, if you want to know more about current developments in inflammatory bowel disease, coeliac disease, or HIV, or you are just curious about what some of those cells that you see in biopsy samples might be doing, I strongly recommend that you invest some money in a copy of this book and some effort in reading it. Furthermore, I suggest beginning with the chapter on "Mouse models of gut inflammation"-such models may not be identical to human inflammatory bowel disease, but at least they give us an opportunity to understand it.

And if you can't remember what CD25 is? Get a copy of Immunobiology by Janeway and Travers (3rd Edition; Current Biology Ltd, 1997); this is another excellent book where no previous knowledge is assumed. There you are - two rave reviews-or three if you count $A$ Study in Scarlet.

A J S MACPHERSON

Gastrointestinal Endosonography. Edited by Van Dam J, Sivak MV. (Pp 298; illustrated; £95.00.) UK: W B Saunders \& Company, 1999. ISBN 0721679897.

This is a collection of work by 31 predominantly North American, European, and Japanese gastroenterologists, digestive surgeons, 
and radiologists. The list of authors includes leading figures in the field of digestive endosonography, namely those who took part in the development of the first pieces of equipment and who described the basic principles of endoscopic ultrasound, and the new generation of practitioners responsible for the most recent developments in this area, particularly the introduction of the endoscopic ultrasound guided puncture. This collective work is complete and exhaustive: it is in large format and divided into seven sections, supplemented by a very detailed and helpful index.

The book is a popular work and the teaching material it contains is very practical, detailed, and useful for beginners. However, the book relies on the experiences of the expert authors, which I find to be of much less interest. Much of their experience is now outdated and there is little scope for discussion of other practices. It contains few illustrations of variable quality. I find it strange that colour Doppler and endoscopic images are grouped at the beginning of the book and reproduced in black and white in appropriate chapters.

In summary, this is a book of high quality work with some good illustrations. The division between the technical sections and those on anatomy is well balanced, which is original to this type of work and is very informative. A number of chapters are extremely useful, particularly those on the linear array echoendoscope and portal hypertension. Some areas covered have less impact, particularly those concerned with the authors' different experiences of gastrooesophageal and retroperitoneal pathology. Generally, retroperitoneal endosonography is poorly covered; biliary echoendoscopy is not discussed at all. This significant gap is an invitation to other authors to publish a work dedicated to biliopancreatic echoendoscopy; a useful supplement to the work of doctors van Dam and Sivak.

L PALAZZO

An Atlas of Diagnostic Radiology in Gastroenterology. Edited by Vallance $R$. (Pp 396; illustrated; $£ 120$ ) Oxford: Blackwell Science, 1998. ISBN 0632050225.

It seems almost unimaginable to me that, somewhere out there, exists a clinical gastroenterologist who would not want to own this book. Maybe I was destined to be the curator of the book review section of Gut just so that a review copy of this majestic atlas might come across my desk. What little effort it is to find words of praise for this tour de force of gastrointestinal radiology.

In one of the most delightfully understated introductions of the century, Roddy MacSween writes that "...this volume brings credit to radiology as a discipline". Oh yes indeed, and so very much more! Dr Vallance and selected colleagues have produced a book in which every single illustration (and there are many hundreds) is crystal clear. There are many radiological texts that are comprehensive, and there is a lesser number in which the pictures are clear. There are few books indeed in which every picture credibly reveals the pathology in a totally convincing manner. I do not believe there is single illustration in this book that is not of a high order, and this applies equally to plain radiographs, barium studies, ultrasound, CT, MRI, angiography, or EUS.

Despite its visual excellence, there are idiosyncrasies. Quite what CT and MRI scans of parotid tumours are doing in a book of GI radiology quite escapes this reviewer. Less satisfactory still are some of the mini essays introducing each system. I suspect most readers will not be particularly enlightened by the two page essays that introduce each organ - too brief to say any more than most clinicians must surely know already. For example, who would learn much from:

Ileostomy enema. The distal small bowel may be examined satisfactorily in patients with an ileostomy by retrograde infusion of barium with or without air, introduced by Foley catheter.

The essays are weak, but the legends and the figures are of exceptional quality. A well constructed legend obviates the need for arrows, or other marks, on the radiograph. In this atlas, arrows do appear from time to time, but they are not intrusive. I suggest that this atlas might very well be added to the extremely short list of books that every gastroenterologist should own.

IAN FORGACS

\section{NOTES}

Sir Frances Avery Jones British Society of Gastroenterology Research Award 2001

Applications are invited by the Education Committee of the British Society of Gastroenterology who will recommend to Council the recipient of the 2001 Award. Applications (TWENTY COPIES) should include:

- A manuscript (2 A4 pages ONLY) describing the work conducted

- A bibliography of relevant personal publications

- An outline of the proposed content of the lecture, including title

- A written statement confirming that all or a substantial part of the work has been personally conducted in the UK or Eire.

Entrants must be 40 years old or less on 31 December 2000 but need not be a member of the Society. The recipient will be required to deliver a 30 minute lecture at the Annual meeting of the Society in Glasgow in March 2001. Applications (TWENTY COPIES) should be made to the Honorary Secretary, British Society of Gastroenterology, $3 \mathrm{St}$ Andrews Place, London NW1 4LB by 1 December 2000.

\section{British Society of Gastroenterology Hopkins Endoscopy Prize 2001}

Applications are invited by the Endoscopy Committee of the British Society of Gastroenterology who will recommend to the Council the recipient of the 2001 Award. Applications (TEN COPIES) should include:

- A manuscript (2 A4 pages ONLY) describing the work conducted

- A bibliography of relevant personal publications

- An outline of the proposed content of the lecture, including title

- A written statement confirming that all or a substantial part of the work has been personally conducted in the UK or Eire.

An applicant need not be a member of the Society. The recipient will be required to deliver a 20 minute lecture at the Annual meeting of the Society in Glasgow in March 2001. Applications (TEN COPIES) should be made to the Endoscopy Section Secretary, British Society of Gastroenterology, $3 \mathrm{St}$ Andrews Place, London NW1 4LB by 1 December 2000.

\section{CORRECTIONS}

An error occurred in the paper by Fisher et al (Gut 2000;46:534-539). Levels of protein C, protein S, antithrombin and factor VII were tenfold too high throughout the manuscript. In the Methods section, normal ranges for protein $\mathrm{C}$, protein $\mathrm{S}$, antithrombin and factor VII should have read 66-122 U/dl, 68-146 $\mathrm{U} / \mathrm{dl}, 75-140 \mathrm{U} / \mathrm{dl}$, and 50-150 U/dl. Similar corrections should apply throughout the Results section and in the legend to figure 1 . This was an editorial error for which Gut apologises.

An error occurred in figure 1 in the paper by Jeppesen and Mortensen (Gut 2000;46:701706). The correct figure is published below. The correct figure appears on the Gut website (www.gutinl.com) and thus diverges from the print version of the May issue. We apologise for any confusion this error may have caused.

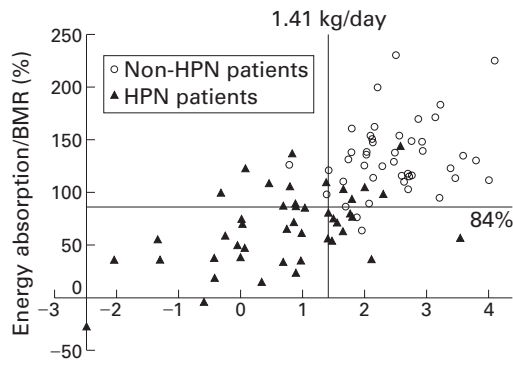

Wet weight (diet-faecal) absorption (kg/day)

Figure 148 hour balance studies defining intestinal failure. Absorption of wet weight and energy in relation to the basal metabolic rate (BMR) calculated by the Harris-Benedict equations in 44 patients managing without parenteral support (non-HPN patients, open circles) and in 45 patients depending on home parenteral nutrition (black triangles). The 5\% confidence limits of the non-HPN patients, defining intestinal failure, are given by the lines. Energy absorption/BMR was $84 \%$ and wet weight absorption $1.41 \mathrm{~kg} /$ day. 